\title{
Mineral affinity analysis: Predicting unknown mineral occurrences with machine learning
}

\author{
SHAUNNA M MORRISON ${ }^{1}$, ANIRUdH PRABHU ${ }^{2}$, AHMED \\ ELEISH $^{2}$, SHWETA NARKAR ${ }^{2}$, PETER ARTHUR FOX ${ }^{2}$, \\ JOSHUA J GOLDEN ${ }^{3}$, ROBERT T DOWNS ${ }^{3}$, SAMUEL \\ PERRY ${ }^{4}$, PETER C BURNS ${ }^{4}$, JOLYON RALPH ${ }^{5}$, AND \\ ROBERT HAZEN ${ }^{1}$
}

${ }^{1}$ Carnegie Institution for Science, Washington, DC

${ }^{2}$ Rensselaer Polytechnic Institute, Troy, NY

${ }^{3}$ University of Arizona, Tucson, AZ

${ }^{4}$ University of Notre Dame, South Bend, IN

${ }^{5}$ Mindat.org, Surray, United Kingdom

The expansion of mineralogical data resources facilitates the development of predictive methods, such as affinity analysis [1], that indentify the location of previously unknown mineral occurrences, deposits or geologic environments, as well as the probabilistic prediction of the likely mineral inventory at any given locality on Earth's surface or, where suitable data is available, other planetary bodies.

Mineral Affinity Analysis [2] can be used to answer many questions of scientific interest. The most basic application of mineral association rules is to identify the most likely location to find a new occurrence of a specific mineral species, with various probability metrics. This can be expanded to identify the most likely location to find a mineral assemblage - an assemblage that could correspond to a certain geologic setting, planetary environment, or deposit type. This will allow researchers interested in locating planetary analogy sites, exploring and assessing resources, or even simply collecting mineral specimens to identify locations that are not currently known to have the mineral or mineral assemblage of interest, but are likely to. This method goes well beyond querying a database to find a match to a list of minerals - it predicts previously unknown information. Furthermore, researchers can use this recommender system to predict what minerals are likely to occur at a specific location of interest. This has a broad range of applicability, from predicting which rare mineral species, indicative of certain planetary conditions or history, are likely to occur on the surface of Mars based on the broad mineralogy detected by remote sensing to predicting the full mineral inventory for mineral collectors who focus on particular localities.

[1] Brin S, Motwani R, Silverstein C (1997) Beyond Market Baskets, ACM SIGMOD Record.

[2] Prabhu et al. (2019) Predicting unknown mineral localities based on mineral associations, AGU, Abstract EP23D-2286 